\title{
Parental illness and life satisfaction among adolescents. A cross-sectional study of moderating effects of school climate indicators
}

\section{Sanne Ellegaard Jørgensen ( $\sim$ saej@sdu.dk)}

University of Southern Denmark https://orcid.org/0000-0003-2293-7315

\section{Lau C. Thygesen}

National Institute of Public Health, University of Sourthen Denmark

Anette Andersen

Steno Diabetes Center Aarhus

\section{Pernille Due}

Novo Nordisk foudation

\section{Susan I Michelsen}

National Institute of Public Health, University of Sourthen Denmark

Research article

Keywords: Parental illness, adolescents, school environment, life satisfaction

Posted Date: April 9th, 2020

DOl: https://doi.org/10.21203/rs.3.rs-20066/v1

License: (c) (i) This work is licensed under a Creative Commons Attribution 4.0 International License. Read Full License 


\section{Abstract}

Background A considerable proportion of adolescents grow up with a seriously or chronically ill parent. School climate is a strong predictor of life satisfaction. Moreover, studies indicate that school climate may operate as a protective factor for adolescents at-risk of low life satisfaction. We examine the relationship between parental illness and life satisfaction and the potential effect modification of the school climate on this association. Furthermore, we describe the use of student counselors among adolescent with and without ill parents. Methods Data include 9,565 students from lower secondary schools and youth education programs who participated in the cross-sectional survey Well-being Despite. Multilevel logistic regression models including joint effect analyses were performed. Results A total of $1,424(14.9 \%)$ students had one or more ill parents. The odds ratio of low life satisfaction among adolescents was $1.21(95 \% \mathrm{Cl}, 0.99-1.48)$ with a physically ill parent with no functional impairment, 1.70 (1.32-2.20) with a physically ill parent with functional impairment, 2.60 (2.01-3.35) with a mentally ill parent, and 3.05 (2.12-4.38) with more than one ill parents, compared to adolescents with no ill parents. Not being part of the classroom community, not trusting your teachers, and wanting more academic support from teachers was more frequent among adolescents with ill parents. Joint effect analysis did not show any buffering effect of school climate indicators in the associations between parental illness and life satisfaction among adolescents. The odds ratio of having talked to a student counselor ranged from 1.26 (1.03-1.54) for adolescents with a physically ill parent with no functional impairment to 2.42 (1.65-3.55) among adolescents with several ill parents, compared to no ill parents. Conclusions Parental illness is strongly associated of low life satisfaction among adolescents, especially among adolescent with a mentally ill parent or several ill parents. For both adolescents with and without an ill parent, negative school climate indicators were strongly associated with low life satisfaction and were more frequent among adolescents with ill parents. Unexpectedly, school climate did not help children of ill parents to achieve a higher life satisfaction, over and above the effect on life satisfaction for all children.

\section{Background}

When a parent becomes ill, the whole family is affected. Physical or mental illness may reduce the parental capacity [1] and result in role reversal, emotional and behavioral problems among the children, and lack of parent's attention [2-4]. Parental illness might even hamper the psychosocial development of the child and pose a potential risk to their mental and social functioning [5-10]. Moreover, parental illness have been associated with lower grade point average (GPA), higher risk of low educational achievement, and attenuated income in adulthood [11-14].

The prevalence of children having a parent with a chronic or serious physical illness is largely unknown. Barkmann, Romer, Watson, \& Schulte-Markwort (2007) estimated that $4.1 \%$ of 4 - to 18 -year-olds in Germany had a parent with a serious physical illness [15]. The prevalence of children with a mentally ill parent has been estimated in several studies. A US National Survey estimate that $18.2 \%$ of parents with children under the age of 18 had a mental illness [16] and an Australian review found that up to one in five young people had a parent with a mental illness [17]. 
Adolescence is a time in life where the child depends on their parents as an emotional anchor and at the same time become increasingly independent throughout their teens. During these years, adolescents tend to spend more time with their peers. Peers influence increasingly in both positive and negative ways, and friendships evolve into more close, supportive, and communicative relationships [18]. Balancing between living a normal youth life and coping with a seriously ill parent can be challenging $[19,20]$. Due to the transitional nature of adolescence, children of this age might be more vulnerable to parental illness than other age groups. A study of the psychological impact of parental cancer found that adolescents show a higher level of emotional symptoms than school-aged children (ages 4-11 years) [21].

Studies that focus on factors that might buffer the possible psychosocial consequences of having a mentally or physically ill parent are scarce. A recent Australian study found that satisfaction with social support from family, friends, and others, was positively associated with several adjustment outcomes including life satisfaction, somatic symptoms, and pro-social behavior among adolescent with parents who had a serious health problem [22]. Qualitative research within this field also identify social support as an important factor in managing life with an ill parent [23]. A qualitative study among adolescents living with parents who have multiple sclerosis identified a strategy of seeking respite through e.g. leisure activities as a useful coping strategy [19]. A review of moderating and mediating factors related to the psychosocial impact of parental cancer suggested that a supportive social network, maintaining contact with peers, and participating in leisure activities were protective against stress response symptoms among the offspring [21].

School is an essential arena for engaging with peers, building friendships, and receiving social support. School might also be a source of respite for adolescent affected by parental illness. Students perception of school climate has shown to be an important predictor of life satisfaction $[24,25]$ and a recent mixed methods review provides sound evidence of the strong influence of school climate on adolescents' overall mental health [26]. Positive relationships with teachers and peers, and positive perceptions of school connectedness (belonging and attachment to school) was associated with increase in adolescents' psychosocial well-being and decrease in mental health problems [26]. The authors propose that proactively enhancing the school climate is well within the reach of schools and teachers [26]. Thus, school climate plays a critical role in promoting the well-being of all students, and studies indicate that school climate might operate as a protective factor for adolescents at-risk due to different stressors in their everyday life by bolstering well-being and academic achievements in vulnerable groups $[27,28]$.

In summary, studies have shown that parental illness can have a great impact on everyday life of the children. Few studies have looked at the impact of parental illness on life satisfaction among adolescents. However, most adolescents do not develop psychological disorders, even in the face of major life events such as parental illness. Moreover, we should strive to improve the quality of life of all adolescents, not merely avoid mental illness. Existing studies on factors that might ease the potential burden of parental illness points towards a supportive social network and a break from the situation at home as important factors. However, most of the existing studies are qualitative and limited to a specific parental diagnose. Given the increasing role of peers during adolescence and the fact that adolescents 
spend most of their day-to-day time in school, the school setting may have the potential to be a resource of support and respite for adolescents living with an ill parent.

The aims of this study are to: 1) examine the relationship between parental illness and life satisfaction among adolescents, 2) investigate the possible modifying effect of school climate indicators (classroom community, academic support from teachers and trust in teachers) in the association between parental illness and life satisfaction, and 3) describe the use of student counselors among adolescent with and without an ill parent.

\section{Methods}

\section{Participants}

The study is based on data from the Danish study Well-being Despite, a cross-sectional survey among students in a nationwide sample of primary and upper secondary schools. Well-being Despite focused on children with an illness or disability and children experiencing illness or death in the immediate family. A random sample of 198 schools were invited to participate, including primary schools, boarding schools, 10th grade school-centers, vocational schools, and high schools. Of the 198 invited schools, 66 agreed to participate. The response rate within schools was $66.6 \%$ resulting in a total of 10,893 participating students. The study population in this article was restricted to students attending 7 th grade or higher $(\mathrm{n}=$ $10,320)$. Missing values due to institution number $(n=27)$ as well as students not answering questions about parental illness $(n=206)$, life satisfaction $(n=36)$, school climate indicators $(n=338)$, age $(n=$ $100)$, and gender $(n=48)$ were excluded from the study population, resulting in a study sample of 9,565 adolescents.

A thorough developing process preceded the final questionnaire. The process included the following: qualitative interviews with children and adolescents who had an ill parent; recurrently consulting a panel of experts holding experience with children of ill parents with regards to contents of the questionnaire as well as formulation of questions; a children's panel consisting of children from the target population who evaluated the questionnaire with regards to relevance of items, language clarification, possible offensive formulations or topics too sensitive to cover in a questionnaire, and ensure meaningful response options to all questions; pilot testing of the questionnaire in different school settings.

Data was collected from September-November 2016. Prior to the data collection, teachers, parents, and students at schools and youth educations received written information about the aim and content of the study, and the procedure of the data collection. This included information about relevant organizations to contact if the students felt a need to talk about their situation. Students completed a web-based questionnaire during school-hours with a teacher present for assistance during completion. The questionnaire took approximately 30 minutes to complete. An audio questionnaire was available for students who preferred this.

\section{Measures}


Life satisfaction was measured by the Cantril ladder, a simple and validated instrument to assess general life satisfaction $[29,30]$. The students were presented with a vertical visual scale (ladder) ranging from 0 to 10, with the following statement: "How are you currently doing? 10 means "the best possible life for you" and 0 means "the worst possible life for you". A score below 6 was considered low life satisfaction [30].

\section{Parental illness}

Students were asked "Do any of the following persons have a serious illness, chronic illness, or a disability?" with the response options: mom; dad; stepmom; stepdad; sibling; no. This question was followed by the question "What illness/disability does your mom/dad/stepparent have?" with the following response options: migraine or frequent headache; apoplexy; visual impairment; hearing impairment; spinal conditions; cancer; arthritis; sclerosis; mental illness (e.g. depression or anxiety); heart disease; kidney disease; other illness/disability. The last response option lead to an open-ended question where students could write specific condition. Moreover, the students were asked about the duration of the illness and a question concerning the degree of limitation caused by the illness/disability: "Think about the past month. How often could your parent(s) not participate in activities because of his/her illness/disability?" with answering options being seldom or never; less than once weekly; weekly; 2-5 times weekly; daily or almost daily; several times a day. Based on this question, parental physical illness was categorized as functionally impairing if the student responded weekly, 2-5 times weekly, daily or almost daily, or several times a day. Mental illness was not categorized according to impairment. III parent in this study was defined as an ill parent (mom/dad) or a cohabiting ill stepparent. The students were categorized according to parental illness as follows: 1) No ill parents, 2) One or several physically ill parents with no functional impairment, 3) one physically ill parent with functional impairment, 4) one mentally ill or mentally and physically ill parent, 5) several ill parents, at least one of them mentally ill or physically ill with functional impairment.

\section{School climate indicators}

Three variables, representing two different aspects of the school climate, were included. Student-teacher relationship measured by trust in teachers and academic support from teachers. Students were presented with the statements "I feel that I can trust my teachers?" and "I wish the teachers at my school asked more about how I am doing academically" with the following response options: Fully agree; agree; neither nor; disagree; strongly disagree. The variables were dichotomized into fully agree/agree vs. neither nor/ disagree/ strongly disagree. The other school climate indicator included was classroom community, measured by the statement "Do you feel as part of the community in class". The response options were the following: always; most of the time; sometimes; seldom or never; there is no community in my class. The item was dichotomized into always/most of the time vs. sometimes/seldom or never/there is no community in my class.

\section{Student counselor experience}


The students' experiences with student counselors were captured by the flowing questions: "Have you talked to a school counselor at the school about specific challenges you have (e.g. your own illness or family illness)?" with response options: Yes, several times; yes, one time; no; there is no student counselor at my school. If no: "Would you like to talk to a student counselor?" with response options Yes; no; don't know. If yes: "I received good help / support from the student counselor" with response options fully agree; agree; neither nor; disagree; strongly disagree.

\section{Composite variables of school climate indicators and parental illness}

To investigate the joint effect of school climate indicators and parental illness we combined information about parental illness and the three indicators of school climate into three new variables. 1) Trust in teachers and parental illness, with students who have no ill parents and trust their teachers as the reference. 2) Academic support from teachers and parental illness, with students who have no ill parents and do not wish, that their teachers asked more about how they are doing academically as the reference. 3) Part of the classroom community and parental illness, with students who have no ill parents and feel included in the classroom community as the reference.

\section{Socioeconomic, demographic, and illness characteristics of the students}

Family socioeconomic position: Students were asked to state their parents'/stepparents' occupation [31]. The answers were coded by the research group into occupational social class ranging from I (high) to $\mathrm{V}$ (low), VI economically inactive parents receiving transfer income, and VII unclassifiable occupation, studying, or missing. Further, these categories were collapsed into four groups: high (I and II), medium (III and IV), low (V and VI), and unclassifiable/students/missing (VII). The highest parental occupational social class for each adolescent was used as an indicator of the adolescents' family socioeconomic position.

Age in years was calculated at the time of data collection using student reported month and year of birth and date of questionnaire completion. Family structure was based on students' reports of whom they live with. Family structure was categorized into living with both parents, living with a single parent, living in a reconstructed family, or other family structure (e.g., living with other family members, foster care, institution, living alone or missing). Ethnicity was based on questions about in which country they and their parents were born and categorized into Danish origin, immigrants, or descendants of immigrants. Students were categorized as having a physical or mental illness based on the question "Do you have..." followed by a list of somatic and mental diagnosis and the response options "other physical illness", "other mental illness" and "I have no illnesses, diagnosis or disabilities".

\section{Statistical analysis}

The data analyses were performed using SAS 9.4. Due to the data structure, students nested within schools, we performed multilevel logistic regression analysis. The level 1-units are individual students 
and level 2-units are schools. Information about the organization of students in classes within schools was not available and could therefore not be accounted for in the analysis. To investigate the possible modifying effect of school climate indicators, we performed joint effect analysis with combined variables. The joint reference category allows us to compare each combination of school climate indicator and parental illness according to the same baseline odds. Furthermore, interaction terms were also tested in the logistic regression model. Statistical significance was set to $p<0.05$ in all analyses. Sensitivity analysis were performed in relation to the cut-point for low life satisfaction (changed from 6 to 5). Moreover, sensitivity analysis adjusting for students' own illnesses were performed, as there is a risk that students' illness might have affected the development of parental mental illness and thus acted as a confounder.

\section{Results}

\section{Description of study population}

Table 1 shows the characteristics of the study population. Of the 9,565 students in the study sample, $1,424(14.9 \%)$ had one or several ill parents/stepparents. The proportion of students having at least one mentally ill parent was $3.8 \%$. In the study population, $98.5 \%$ of the adolescents were between 13 and 20 years old, the full age range being 12 to 26 years. The mean age ranged from 16.9 to 17.4 across parental illness status. Approximately half of the students reporting no ill parents were female $(55.3 \%)$ whereas a larger proportion of the students reporting an ill parent were female, especially among students with a mentally ill parent (74.6\% female) and students with several ill parents (81.4\%). A smaller proportion of the adolescent with an ill parent had high family socioeconomic position and lived with both parents, compared with adolescents who did not have an ill parent. This is particularly pronounced among adolescents with several ill parents where $19.4 \%$ have high family socioeconomic position compared to $47.7 \%$ among students with no ill parents. A slightly smaller proportion of adolescents with ill parents have siblings and more students with several ill parents attend vocational schools compared to adolescents with no ill parents. A markedly higher proportion of adolescent with an ill parent have reported mental or physical illness, for instance $54.3 \%$ of adolescents with several ill parents have reported having a physical illness themselves compared to $30.9 \%$ of adolescents with no ill parents.

With regards to school climate indicators, a larger proportion of adolescents with ill parents do not feel as part of the classroom community, do not trust their teachers, and wish that their teachers asked more about how they are doing academically, especially among students with mentally ill parents and more than one ill parent. Moreover, the frequency of low life satisfaction is markedly higher among adolescents with ill parents than among adolescent without ill parents.

Most of the adolescents with an ill parent have an ill mother and have had an ill parent(s) for at least four years (Table 2). The most frequently reported physical illnesses among parents with no functional impairment were spinal conditions (e.g. herniated disc) (17.5\%), migraine or frequent headaches (16.0\%), arthritis $(13.3 \%)$, cancer $(11.3 \%)$, and heart disease (9.5\%). For parents with a physical illness and 
functional impairment the most frequently reported condition were spinal conditions (28.1\%), arthritis (19.7\%), migraine or frequent headaches (16.1\%), cancer (15.2\%), and apoplexy (10.7\%) (not shown in table). Information about the specific mental illness was not available.

\section{Association between parental illness, school climate indicators, and life satisfaction among adolescents}

Table 3 shows the odds ratio of low life satisfaction, adjusted for gender, age, and family socioeconomic position, across parental illness status and school climate indicators. The odds ratio of low life satisfaction was significantly higher among adolescent with one physically ill parent with functional impairment (OR 1.70, 95\% Cl 1.32-2-20), adolescents with one mentally ill parent (OR 2.60, 95\% Cl 1.993.31), and adolescents with several ill parents (OR 3.05, 95\% Cl 2.12-4.38), compared to adolescents with no ill parents. For adolescents with physically ill parent(s) with no functional impairment, the odds are slightly increased, but not significant (Table 3). Changing the cut-point for low life satisfaction from 6 to 5 did not alter the results (results not shown in table). Adjusting for physical and mental illness among the adolescents resulted in slightly smaller effect estimates but did not alter the overall findings (not shown).

The odds ratio of low life satisfactions was significantly higher for students who did not agree in trusting their teachers (OR 2.13,95\% Cl: 1.91-2.37), for students who wished that their teacher asked more about their how they are doing academically (OR 1.44,95\% Cl: 1.29-1.61), and among students who did not feel as part of the classroom community (OR $3.91,95 \%$ Cl: $3.47-4.41$ ).

\section{Joint effect of school climate indictors and parental illness on life satisfaction among adolescents}

Figure 1 shows results of the joint effect analysis, adjusted for age, gender, and family socioeconomic position. The joint effect analyses of parental illness and trust in teachers (Figure 1A) showed that the highest odds ratios of low life satisfaction was seen among adolescents with a mentally ill parent (OR 5.90, Cl 95 \% 4.17-8.34) and adolescents with several ill parents (OR 5.66, Cl 95 \% 3.39-9.44) and low trust in teachers compared to adolescents with no ill parents who trust their teachers. The multiplicative interaction term between parental illness and trust their teachers was not significant $(p=0.69)$. The joint effect of parental illness and academic support from teachers (Figure 1B) resulted in an odds ratio of low life satisfaction of 3.86 (Cl $95 \%$ 2.56-5.84) among adolescents with a mentally ill parent and 4.30 (Cl 95 $\%$ 2.45-7.54) for adolescents with several ill parents, who were unsatisfied with the academic support from teachers. The multiplicative interaction term between parental illness and academic support from teachers was not significant $(p=0.26)$. The joint effect of parental illness and not being part of the classroom community (Figure 1C) was highest among adolescents with a mentally ill parents (OR 6.16, $\mathrm{Cl} 95$ \% 3.90-9.72) and adolescents with several ill parents (OR 7.44, Cl 95 \% 3.91-14.20). The interaction term between parental illness and classroom community was significant $(p=0.02)$. The interaction estimates support that, on a relative scale, being part of the classroom community is less important to 
students with an ill parent compared to adolescents with no ill parents, supporting an antagonistic multiplicative interaction.

\section{Student counselor experience}

A larger proportion of adolescents with an ill parent reported having talked to a student counselor than among adolescents with no ill parents (Table 4). The odds ratio of having talked to a student counselor was highest among adolescents with several ill parents compared to adolescents with no ill parents (OR 2.42, 95\% Cl 1.65-3.55). Across parental illness status, between half and two-thirds of the students who had talked to a student counselor found the counseling helpful. Among students who had not talked to a student counselor, the vast majority did not express a wish to do so. However, adolescents with a mentally ill parent or several ill parents who did not talk to a student counselor more frequently reported that they wished to talk to a student counselor and adolescents with several ill parents had a threefold odds (OR 3.04, 95\% Cl:1.69-5.46) of wanting to talk to a student counselor, compared to adolescents with no ill parents.

\section{Discussion}

The prevalence of child-reported parental illness in this study was $14.9 \%(n=1,427), 3.8 \%$ having one or more mentally ill parents. The prevalence of low life satisfaction was markedly higher among adolescent with an ill parent. Among adolescents with more than one ill parent the prevalence of low life satisfaction was $47.3 \%$ and for adolescents with a mentally ill parent the prevalence was $37.9 \%$, whereas $16.9 \%$ of adolescents with no ill parents reported low life satisfaction. We found a negative association between parental illness and life satisfaction among adolescent when controlling for age, gender, and socioeconomic position. The highest odds ratio of low life satisfaction was seen among adolescents with several ill parents who had threefold odds of low life satisfaction (OR: 3.05, 95\% Cl: 2.12-4.38) compared to adolescents with no ill parents.

Adolescents who were exposed to both parental illness and negative school climate had an odds ratio as high as 7.5 (95\% Cl:3.91-14.20) of low life satisfaction, compared to adolescent who for instance felt included in the classroom community and had no ill parents. No support was found for a buffering effect of school climate indicators in the association between parental illness and life satisfaction. For classroom community however, the opposite trend was seen; not being part of the classroom community seem more important in relation to life satisfaction to those without an ill parent than to those with an ill parent. Adolescents with ill parents had greater odds of having talked to a student counselor. The results also revealed that among adolescents who had no experience with student counselors, students with a mentally ill parent or several ill parents more frequently wished to talk to a student counselor. A substantial proportion of the students did not know, if they wished to talk to a student counselor, which might indicate a lack of knowledge about what the student counselor can offer. 
The prevalence of parental mental illness estimated in this study is lower than previous estimations up to $20 \%$ [17]. The lower prevalence of parental mental illness could be due to the wording of the question concerning parental illness in the questionnaire. The students were asked if any of the following persons had a serious or chronic illness, and only after confirming to this, the students were presented with a list of somatic diagnosis and the response option "mental illness". The use of the words "serious" and "chronic" might not appeal to students with a mentally ill parent. Moreover, presenting a list of mental illnesses could have reminded students of potential parental mental illness. Nondisclosure of parental illness could also be due unwillingness to report the illness or because the adolescent simply does not know about the illness. Moreover, we found a notable gender differences in reporting of parental illness.

The association between parental illness and life satisfaction among adolescent coincide with Pakenham \& Bursnall [32] who found lower life satisfaction among children of parents with multiple sclerosis compared to children with healthy parents. Many previous studies have looked at the impact of specific parental diagnosis on children, for instance parental cancer or multiple sclerosis [33-36]. We studied parental illness regardless of diagnosis and found great differences in life satisfaction depending on whether the parental illness was physical or mental, related impairment of the ill parent, and number of ill parents. Differences in the odds of low life satisfaction across parental illness status is in line with the findings of Van der Werf et al. [4] and Krattenmacher et al [37]. Van der Werf et al. [4] found that students living with a mentally ill parent were at greater risk of negative consequences in their daily life than those living with a physically ill parents. Likewise, Krattenmacher et al [37] found a higher frequency of emotional and behavioral problems among children living in families with parental mental illness, than

in families with prenatal cancer. A greater vulnerability in children of parents with mental disorders might partly be explained by the heritability of mental illness [38].

In the studies mentioned above, there is no distinction between the degree of parental physical illness. Our results show a great overlap between the most frequent diagnoses in the two categories of physically ill parents; physically ill with no functional impairment and physically ill with functional impairment. This indicates that it is not sufficient to distinguish between mental and physical illness in future studies, but also the degree of impairment by the physical illness. This is in line with the Stoeckel \& Weissbrod [8] who found that greater impact of the parental illness was negatively correlated with adolescent's depression, anxiety, and life satisfaction.

\section{Study strengths and limitations}

This study is, to our knowledge, the first to look at school climate as a potential protective factor for adolescents growing up with an ill parent and explore the use of student counselors across parental illness status. The study is based on a large, nationwide sample of Danish children and youth attending school or a youth education program. Students from all types of youth educations were represented in the sample, although the response rate within schools was moderate. In contrast to many previous studies, adolescents were not recruited through their ill parent or as a result of contact with the healthcare 
system; in this study parental illness was identified in a random sample of adolescents, reducing the risk of selection bias.

Life satisfaction was measured by a single, self-reported indicator, the Cantril Ladder. This instrument, has shown to be an appropriate measurement tool as a wide approach to psychosocial adolescent health $[29,30]$. The measurement of school climate is also based on self-report by the adolescents. A recent study among German school-aged children found that student's individual perception of class climate was a strong predictor of life satisfaction whereas the overall learning climate in school classes were only weakly associated with life satisfaction [25].

There are several limitations to consider in this study. Due to the cross-sectional design of this study, causal directions among variables cannot be established. It is unlikely that low life satisfaction among children will cause parental illness. However, because parental illness is based on the subjective assessment by the adolescent, low life satisfaction may lead to a more adverse estimation of parental illness. Moreover, as mentioned earlier, the child-reported parental illness may have led to an underestimation due to nondisclosure of illnesses. Subjective assessment of parental serious or chronic illness has shown to be a strong predictor of psychosocial functioning in children [7]. It would, however, have been enlightening with multiple data sources for the measurement of parental illness.

In this study, we included all types of parental illness, regardless of diagnosis. This is a strength of the study as we comprehend also the rare diagnoses. Moreover, the results underline the difference between mental and physical illness and the importance of the degree of impairment by the parental illness in relation to life satisfaction of the offspring. Collapsing a continuum of illness into broad categories does however pose the risk of averaging out significant differential effects. For instance, we were not able to consider if the parental illness was life-threatening or not.

Adolescents attending high school were overrepresented in the study population compared to vocational education programs. Furthermore, the study does not include adolescents not attending a youth education program. There is a potential risk that we are exploring a particularly high functioning sample of adolescents with ill parents, if those who are most negatively affected by parental illness do not attend youth educations or more often attend vocational education programs. This may have introduced selection bias and caused an underestimation of the effect of parental illness on life satisfaction.

\section{Implication for research and practice}

This study adds to the knowledge about children living with a seriously or chronically ill parent and sheds light on the impact of mental, physical, and functionally impairing illnesses. The variation in strength of the association across the different categories of parental illness suggest that when intervening in families with parental illness, it might not be the diagnosis that determine whether the life satisfaction and well-being of the children is at stake, but the degree of impairment and interruption of everyday life.

Future research should explore the gender differences in reporting of parental illness and explore if this variance also exists in the adaptation to parental illness. Moreover, identifying predictive and protective 
factors for life satisfaction and well-being among children and adolescents with a serious or chronically ill parent is necessary in order to develop effective and targeted interventions, inform teachers, healthcare professionals, and the social network around these families. Furthermore, identifying those who are thriving despite parental illness will help prioritize resources.

\section{Conclusions}

We found a strong association between parental illness and life satisfaction among adolescents, with the highest odds of low life satisfaction among adolescent with a mentally ill parent and several ill parents. Life satisfaction among adolescents with and without an ill parent was associated with school climate indicators. School climate indicators did not act as an effect modifier in the association between parental illness and life satisfaction. However, adolescents with ill parents more frequently reported that they did not trust their teachers, were unsatisfied with the academic support from teachers, and did not feel as part of the community in the class. This underlines the need and importance of strengthening studentteacher relationship and classroom connectedness in adolescents with ill parents. Moreover, such interventions could be targeted all children and would be beneficial to all students, as the school environment is important for life satisfaction for all children.

This study also reveals, that a great proportion of adolescents were unsure about whether they would like to talk to a student counselor, indicating a lack of knowledge about what the student counselor can offer. Thus, student counselors might be a potential unrecognized source of support for students experiencing parental illness.

\section{Abbreviations}

OR

Odds ratio.

$\mathrm{Cl}$

Confidence interval.

SD

Standard deviation.

\section{Declarations}

\section{Ethics approval and consent to participate:}

In Denmark, research projects not including human biological material, are not obligated to obtain acceptance by an ethical committee [39]. The Well-being Despite study is declared to the Data Protection Agency at the University of Southern Denmark (J.nr. 10.755). Students, parents, and teachers were informed about the aim of the study, that participation was voluntary, and data would be stored safely. Parents of children in lower secondary school were informed through an online parental intranet prior to 
data collection, giving parents the opportunity to exclude their child from participating in the survey. Adolescents attending youth education programs received an email with information about the study prior to data collection informed.

\section{Consent for publication}

Not applicable.

\section{Availability of data and materials:}

The datasets used during the current study are available from the corresponding author on reasonable request.

\section{Competing interests:}

The authors declare that they have no competing interests.

\section{Funding:}

The Egmont Foundation, Liljeborgfonden, Helsefonden and University of Sourthen Denmark funded this study. The funding parties did not take part in the design, data collection, analyses, manuscript write-up or decision to publish this study.

\section{Authors' contributions:}

SEJ, LCT, AA, PD, and SIM took part in planning and designing the study. SEJ drafted this paper and performed the statistical analyses. LCT provided supervision for the statistical analyses. All authors took part in the interpretation of the results, commented on the manuscripts throughout the writing process, and reviewed and approved the final version of the manuscript.

\section{Acknowledgements:}

The authors wish to thank the schools and students across Denmark who participated in the survey and made the study possible.

\section{Authors' information (optional)}

\section{References}

1. Leinonen JA, Solantaus TS, Punamäki RL. Parental mental health and children's adjustment: The quality of marital interaction and parenting as mediating factors. J Child Psychol Psychiatry Allied Discip. 2003 Feb;44(2):227-41.

2. Tabak I, Zabłocka-Żytka L, Ryan P, Poma SZ, Joronen K, Viganò G, et al. Needs, expectations and consequences for children growing up in a family where the parent has a mental illness. Int $\mathrm{J}$ Ment 
Health Nurs. 2016;26:319-29.

3. Sieh DS, Visser-Meily JMA, Meijer AM, Sebastian Sieh D, Maria Augusta Visser-Meily J, Marie Meijer A. Differential Outcomes of Adolescents with Chronically III and Healthy Parents. J Child Fam Stud. 2013; 22:209-18. Available from: Fs10826-012-9570-8.pdf.

4. Van der Werf HM, Luttik MLA, Francke AL, Roodbol PF, Paans W. Students growing up with a chronically ill family member; a survey on experienced consequences, background characteristics, and risk factors. BMC Public Health. 2019;19(1):1486.

5. Nagl-Cupal M, Daniel M, Koller MM, Mayer H. Prevalence and effects of caregiving on children. J Adv Nurs. 2014;70(10):2314-25.

6. Sieh DS, Meijer AM, Oort FJ, Visser-Meily JMA, Van der Leij DAV. Problem Behavior in Children of Chronically III Parents: A Meta-Analysis. Clin Child Fam Psychol Rev. 2010;13(4):384-97.

7. Sieh DS, Visser-Meily JMA, Oort FJ, Meijer AM. Risk factors for problem behavior in adolescents of parents with a chronic medical condition. Eur Child Adolesc Psychiatry. 2012 Aug 28;21(8):459-71.

8. Stoeckel M, Weissbrod C. Growing up with an ill parent: An examination of family characteristics and parental illness features. Fam Syst Heal. 2015;33(4):356-62.

9. Houck CD, Rodrigue JR, Lobato D. Parent - Adolescent Communication and Psychological Symptoms among Adolescents with Chronically III Parents. J Pediatr Psychol. 2007;32(5):596-604.

10. Dean K, Green MJ, Laurens KR, Kariuki M, Tzoumakis S, Sprague T, et al. The impact of parental mental illness across the full diagnostic spectrum on externalising and internalising vulnerabilities in young offspring. Psychological Medicine. 2018.

11. Joergensen AC, Kjaer Urhoj S, Nybo Andersen A-M. Primary school achievement and socioeconomic attainment in individuals affected by parental cancer in childhood or adolescence: a Danish nationwide register-based study. J Epidemiol Community Health. 2018.

12. Moberg JY, Laursen B, Koch-Henriksen N, Thygesen LC, Brødsgaard A, Soelberg Sørensen P, et al. Employment, disability pension and income for children with parental multiple sclerosis. Mult Scler J. 2017;23(8):1148-56.

13. Chikhradze N, Knecht C, Metzing S. Young carers: growing up with chronic illness in the family -a systematic review 2007-2017. J Compassionate Heal Care. 2017;4(12).

14. Lin A, Di Prinzio P, Young D, Jacoby P, Whitehouse A, Waters F, et al. Academic Performance in Children of Mothers With Schizophrenia and Other Severe Mental IIIness, and Risk for Subsequent Development of Psychosis: A Population-Based Study. Schizophr Bull. 2017;43(1):205-13.

15. Barkmann C, Romer G, Watson M, Schulte-Markwort M. Parental physical illness as a risk for psychosocial maladjustment in children and adolescents: epidemiological findings from a national survey in Germany. Psychosomatics. 2007;48:476-81.

16. Stambaugh LF, Forman-Hoffman V, Williams J, Pemberton MR, Hedden SL, Bose J. Prevalence of serious mental illness among parents in the United States: results from the National Survey of Drug Use and Health, 2008-2014. Annals of Epidemiology journal. 2017. 
17. Reupert AE, Maybery J, Kowalenko D, Maybery NM, Kowalenko D. NM. Children whose parents have a mental illness: prevalence, need and treatment. Med J Aust. 2013 Aug;5(3 Suppl):7-9. 1(.

18. Steinberg L, Morris A. ADOLESCENT DEVELOPMENT. Annu Rev Psychol. 2001;52:83-110.

19. Mauseth T, Hjälmhult E. Adolescents' experiences on coping with parental multiple sclerosis: A grounded theory study. J Clin Nurs. 2016;25(5-6):856-65.

20. Moberg JY, Larsen D, Brødsgaard A. Striving for balance between caring and restraint: young adults' experiences with parental multiple sclerosis. J Clin Nurs. 2017;26(9-10):1363-74.

21. Huizinga GA, Visser A, Zelders-Steyn YE, Teule JA, Reijneveld SA, Roodbol PF. Psychological impact of having a parent with cancer. Eur J Cancer. 2011;47(Suppl 3):239-46.

22. Pakenham KI, Cox S. Effects of Benefit Finding, Social Support and Caregiving on Youth Adjustment in a Parental Illness Context. J Child Fam Stud. 2018.

23. Yamamoto R, Keogh B. Children's experiences of living with a parent with mental illness: A systematic review of qualitative studies using thematic analysis. J Psychiatr Ment Health Nurs. 2018;25(2):131-41.

24. Suldo SM, McMahan MM, Chappel AM, Loker T. Relationships Between Perceived School Climate and Adolescent Mental Health Across Genders. School Ment Health. 2012;4(2):69-80.

25. Rathmann K, Herke MG, Hurrelmann K, Richter M. Perceived class climate and school-aged children's life satisfaction: The role of the learning environment in classrooms. PLoS One. 2018;13(2).

26. Aldridge JM, McChesney K. The relationships between school climate and adolescent mental health and wellbeing: A systematic literature review. Int J Educ Res. 2018;88:121-45.

27. Masten AS, Herbers JE, Cutuli JJ, Lafavor TL. Promoting competence and resilience in the school context. Professional School Counseling. 2008.

28. O'Malley M, Voight A, Renshaw TL, Eklund K. School climate, family structure, and academic achievement: a study of moderation effects. Sch Psychol Q. 2015;30(1):142-57.

29. Mazur J, Szkultecka-Dębek M, Dzielska A, Drozd M, Małkowska-Szkutnik A. What does the Cantril Ladder measure in adolescence? Arch Med Sci. 2018;14:182-9.

30. Levin KA, Currie C. Reliability and Validity of an Adapted Version of the Cantril Ladder for Use with Adolescent Samples. Soc Indic Res. 2014;119:1047-63.

31. Pförtner T-K, Günther S, Levin KA. The use of parental occupation in adolescent health surveys. An application of ISCO-based measures of occupational status. J Epidemiol Community Heal. 2014;69:177-84.

32. Pakenham KI, Bursnall S. Relations between social support, appraisal and coping and both positive and negative outcomes for children of a parent with multiple sclerosis and comparisons with children of healthy parents. Clin Rehabil. 2006;20(8):709-23.

33. Diareme S, Tsiantis J, Romer G, Tsalamanios E, Anasontzi S, Paliokosta E, et al. Psychological impact of having a parent with cancer. J Child Fam Stud. 2012 Mar 1;22(3):100. 
34. Faccio F, Ferrari F, Pravettoni G, Maceachnie LH, Larsen HB, Egerod I, et al. Adolescents' experiences on coping with parental multiple sclerosis: A grounded theory study. J Child Fam Stud. 2012;22(1):1-16. cited 2015 Feb 18 ;(.

35. Krattenmacher T, Kühne F, Ernst J, Bergelt C, Romer G, Möller B. Parental cancer: Factors associated with children's psychosocial adjustment - a systematic review. J Psychosom Res. 2012;72(5):34456.

36. Möller B, Barkmann C, Krattenmacher T, Kühne F, Bergelt C, Beierlein V, et al. Children of cancer patients: prevalence and predictors of emotional and behavioral problems. Cancer. 2014 Aug 1; 120(15):2361-70.

37. Krattenmacher T, Kühne F, Halverscheid S, Wiegand-Grefe S, Bergelt C, Romer G, et al. A comparison of the emotional and behavioral problems of children of patients with cancer or a mental disorder and their association with parental quality of life. J Psychosom Res. 2014;76(3):213-20.

38. Assary E, Vincent JP, Keers R, Pluess M. Gene-environment interaction and psychiatric disorders: Review and future directions. Semin Cell Dev Biol. 2018;77:133-43.

39. Thygesen LC, Daasnes C, Thaulow I, Brønnum-hansen H. Introduction to Danish (nationwide) registers on health and social issues: Structure, access, legislation, and archiving. Scand J Public Health. 2011;39(7):12-6.

\section{Tables}

Table 1. Characteristics of the study population by parental illness: socioeconomic, demographic, school climate, and life satisfaction. 


\begin{tabular}{|c|c|c|c|c|c|c|}
\hline & $\begin{array}{l}\text { No ill } \\
\text { parents }\end{array}$ & $\begin{array}{l}\text { Physically ill parent(s), } \\
\text { no functional impairment }\end{array}$ & $\begin{array}{l}\text { Physically ill parent, } \\
\text { functionally impaired }\end{array}$ & $\begin{array}{l}\text { Mentally } \\
\text { ill parent }\end{array}$ & $\begin{array}{l}\text { Several } \\
\text { ill } \\
\text { parents }\end{array}$ & $P^{1}$ \\
\hline Total N (\%) & $\begin{array}{l}8141 \\
(85.1)\end{array}$ & $688(7.2)$ & $325(3.4)$ & $282(2.9)$ & $129(1.4)$ & \\
\hline Age (mean (SD)) & $\begin{array}{l}16.9 \\
(1.45)\end{array}$ & $16.9(1.40)$ & $17.2(1.59)$ & $\begin{array}{l}17.0 \\
(1.67)\end{array}$ & $\begin{array}{l}17.4 \\
(1.61)\end{array}$ & $<.0001$ \\
\hline Age range & $12-26$ & $12-25$ & $12-26$ & $13-26$ & $13-25$ & \\
\hline Gender (\% female) & 55.3 & 63.8 & 68.6 & 74.6 & 81.4 & $<.0001$ \\
\hline Family socioeconomic position (\%) & & & & & & $<.0001$ \\
\hline High & 47.7 & 42.0 & 34.5 & 34.4 & 19.4 & \\
\hline Medium & 29.9 & 33.0 & 28.6 & 29.8 & 27.9 & \\
\hline Low & 6.5 & 11.3 & 19.1 & 13.1 & 30.2 & \\
\hline $\begin{array}{l}\text { Students/missing/ } \\
\text { unclassifiable }\end{array}$ & 15.9 & 13.7 & 17.9 & 22.7 & 22.5 & \\
\hline Family structure (\%) & & & & & & $<.0001$ \\
\hline Living with both parents & 63.7 & 61.6 & 55.4 & 42.2 & 35.7 & \\
\hline Living with single parent & 15.4 & 16.7 & 17.9 & 23.8 & 25.6 & \\
\hline Reconstructed family & 14.9 & 16.1 & 19.4 & 20.9 & 24.0 & \\
\hline $\begin{array}{l}\text { Other (foster care, institution, living } \\
\text { alone or missing) }\end{array}$ & 6.0 & 5.5 & 7.4 & 13.1 & 14.7 & \\
\hline $\begin{array}{l}\text { Ethnicity (\% immigrants or descendants of } \\
\text { immigrants) }\end{array}$ & 17.2 & 19.5 & 16.0 & 19.5 & 14.7 & 0.3829 \\
\hline Have siblings (\%) & 96.4 & 95.5 & 93.5 & 93.6 & 93.8 & 0.0124 \\
\hline School type $^{2}(\%)$ & & & & & & 0.0002 \\
\hline Primary school/10th grade school-center & 6.4 & 5.8 & 4.0 & 6.0 & 5.4 & \\
\hline Boarding school & 10.2 & 7.9 & 10.8 & 7.5 & 3.1 & \\
\hline Vocational school & 5.8 & 6.7 & 8.6 & 7.8 & 14.7 & \\
\hline High School & 77.6 & 79.7 & 76.6 & 78.7 & 76.7 & \\
\hline Self-reported physical illness (\%) & 30.9 & 41.7 & 48.3 & 43.6 & 54.3 & $<.0001$ \\
\hline Self-reported mental illness (\%) & 18.1 & 21.5 & 22.8 & 35.8 & 53.5 & $<.0001$ \\
\hline $\begin{array}{l}\text { I can trust my teachers (\% neither } \\
\text { nor/disagree/strongly disagree) }\end{array}$ & 40.0 & 37.5 & $45.9^{\prime} 5$ & 51.1 & 49.6 & $<.0001$ \\
\hline $\begin{array}{l}\text { I wish the teachers at my school asked } \\
\text { more about how I am doing academically } \\
\text { (\% strongly agree/agree) }\end{array}$ & 32.7 & 32.3 & 37.9 & 35.1 & 41.9 & 0.0803 \\
\hline $\begin{array}{l}\text { I am part of the classroom community } \\
\text { (\% sometimes/ seldom or never/there is no } \\
\text { community) }\end{array}$ & 16.1 & 18.2 & 24.9 & 28.0 & 31.8 & $<.0001$ \\
\hline Low life satisfaction (\%) & 16.9 & 20.8 & 29.2 & 37.9 & 47.3 & $<.0001$ \\
\hline
\end{tabular}

${ }^{1}$ Chi-square test or ANOVA as appropriate

${ }^{2}$ Due to small numbers, unknown youth education is placed in the "High school" category.

Table 2. Parental illness characteristics, N (\%) 


\begin{tabular}{|l|l|l|l|l|}
\hline & $\begin{array}{l}\text { Physically ill parent/parents, no } \\
\text { functional impairment } \\
\text { N=688 }\end{array}$ & $\begin{array}{l}\text { One physically ill parent, } \\
\text { functionally impaired } \\
\text { N=325 }\end{array}$ & $\begin{array}{l}\text { One mentally ill } \\
\text { parent } \\
\text { N=282 }\end{array}$ & $\begin{array}{l}\text { Several ill } \\
\text { parents } \\
\text { N=129 }\end{array}$ \\
\hline $\begin{array}{l}\text { Parent with illness or } \\
\text { disability }\end{array}$ & & & & \\
\hline Ill mother & $330(48.0)$ & $204(62.8)$ & $182(64.2)$ & - \\
\hline Ill father & $254(36.9)$ & $110(33.8)$ & $95(33.7)$ & - \\
\hline Ill stepmother/father & $22(3.2)$ & $11(3.4)$ & $6(2.1)$ & - \\
\hline Several ill parents & $82(11.9)$ & - & - & $129(100)$ \\
\hline Illness duration ${ }^{1}$ & & & & \\
\hline 0-4 years & $231(33.6)$ & $122(37.5)$ & $75(26.6)$ & $19(14.7)$ \\
\hline$>4$ years & $181(26.3)$ & $126(38.8)$ & $103(36.5)$ & $42(32.6)$ \\
\hline From birth & $215(31.3)$ & $59(18.2)$ & $75(26.6)$ & $63(48.8)$ \\
\hline Missing & $61(8.9)$ & $18(5.5)$ & $29(10.3)$ & $5(3.9)$ \\
\hline $\begin{array}{l}\text { Cohabiting with ill } \\
\text { parent }\end{array}$ & $616(89.5)$ & $273(84.0)$ & $186(66.0)$ & $111(86.1)$ \\
\hline Type of illness & & & & \\
\hline Physical illness & $688(100)$ & & - & $47(36.4)$ \\
\hline Mental illness & - & $325(100)$ & $181(64.2)$ & $8(6.2)$ \\
\hline $\begin{array}{l}\text { Mental and physically } \\
\text { illness }\end{array}$ & - & - & - & $74(57.4)$ \\
\hline
\end{tabular}

${ }^{1}$ If multiple ill parents, the duration refers to the parent who have the longest illness duration.

Table 3. Odds ratio of low life satisfaction by parental illness and school climate indicators

\begin{tabular}{|c|c|c|}
\hline & Crude OR (95 \% CI) & Adjusted OR (95 \% CI) \\
\hline \multicolumn{3}{|l|}{ Parental illness } \\
\hline No ill parents & 1.00 (ref.) & 1.00 (ref.) \\
\hline Physically ill parent(s), no functional impairment & $1.27(1.04-1.54)$ & $1.20(0.98-1.46)$ \\
\hline Physically ill parent, functional impairment & $1.98(1.54-2.53)$ & $1.70(1.32-2.20)$ \\
\hline Mentally ill parent & $2.98(2.32-3.83)$ & $2.60(1.99-3.31)$ \\
\hline Several ill parents & $3.98(2.79-5.69)$ & $3.05(2.12-4.38)$ \\
\hline \multicolumn{3}{|l|}{ I can trust my teachers } \\
\hline Strongly agree/agree & 1.00 (ref.) & 1.00 (ref.) \\
\hline Neither nor/disagree/strongly disagree & $2.28(2.05-2.54)$ & $2.13(1.91-2.37)$ \\
\hline \multicolumn{3}{|c|}{ I wish the teachers at my school asked more about how I am doing academically } \\
\hline Neither nor/disagree/strongly disagree & 1.00 (ref.) & 1.00 (ref.) \\
\hline Strongly agree/agree & $1.53(1.37-1.70)$ & $1.44(1.29-1.61)$ \\
\hline \multicolumn{3}{|l|}{ I am part of the classroom community } \\
\hline Always/most of the time & 1.00 (ref.) & 1.00 (ref.) \\
\hline Sometimes/ seldom or never/there is no community & $4.25(3.78-4.79)$ & $3.91(3.47-4.41)$ \\
\hline
\end{tabular}

${ }^{1}$ Adjusted for gender, age, and socioeconomic position

Table 4. Student counselor experience by parental illness, \% (n) and odds ratio of student counselor experiences 


\begin{tabular}{|c|c|c|c|}
\hline & $\%(\mathrm{n})$ & Adjusted $\mathrm{OR}^{1}(95 \% \mathrm{CI})$ & Type III test, $p$ \\
\hline Talked to student counselor, $N=9280$ & & & $<.0001$ \\
\hline No ill parents & $17.1(1342)$ & 1.00 (ref.) & \\
\hline Physically ill parent(s), no functional impairment & $20.6(141)$ & $1.26(1.03-1.54)$ & \\
\hline Physically ill parent, functional impairment & $28.6(92)$ & $1.74(1.34-2.26)$ & \\
\hline Mentally ill parent & $35.7(99)$ & $2.52(1.94-3.29)$ & \\
\hline Several ill parents & $38.3(49)$ & $2.42(1.65-3.54)$ & \\
\hline \multicolumn{4}{|l|}{ Among students who talked to a student counselor, $\mathrm{N}=1725$} \\
\hline Strongly agree/ agree that it was helpful & & & 0.31 \\
\hline No ill parents & $61.2(820)$ & 1.00 (ref.) & \\
\hline Physically ill parent(s), no functional impairment & $61.4(86)$ & $1.03(0.72-1.48)$ & \\
\hline Physically ill parent, functional impairment & $51.1(47)$ & $0.71(0.46-1.09)$ & \\
\hline Mentally ill parent & $67.7(67)$ & $1.36(0.89-2.12)$ & \\
\hline Several ill parents & $59.2(29)$ & $1.01(0.56-1.82)$ & \\
\hline \multicolumn{4}{|c|}{ Among students who did not talk to a student counselor, $\mathrm{N}=7478$} \\
\hline Wish to talk to a student counselor & & & 0.0003 \\
\hline No ill parents & $8.8(565)$ & 1.00 (ref.) & \\
\hline Physically ill parent(s), no functional impairment & $6.3(34)$ & $0.69(0.48-1.00)$ & \\
\hline Physically ill parent, functional impairment & $9.7(22)$ & $1.14(0.72-1.81)$ & \\
\hline Mentally ill parent & $11.8(21)$ & $1.52(0.94-2.46)$ & \\
\hline Several ill parents & $21.8(17)$ & $3.04(1.69-5.46)$ & \\
\hline Do not know if they wish to talk to a student counselor & & & 0.32 \\
\hline No ill parents & $23.6(1523)$ & 1.00 (ref.) & \\
\hline Physically ill parent(s), no functional impairment & $22.4(120)$ & $0.86(0.69-1.06)$ & \\
\hline Physically ill parent, functional impairment & $24.3(55)$ & $0.96(0.70-1.32)$ & \\
\hline Mentally ill parent & $30.3(54)$ & $1.31(0.93-1.84)$ & \\
\hline Several ill parents & $23.1(18)$ & $1.00(0.57-1.75)$ & \\
\hline
\end{tabular}

${ }^{1}$ Adjusted for gender, age, and socioeconomic position

\section{Figures}




\section{Trust in teachers}
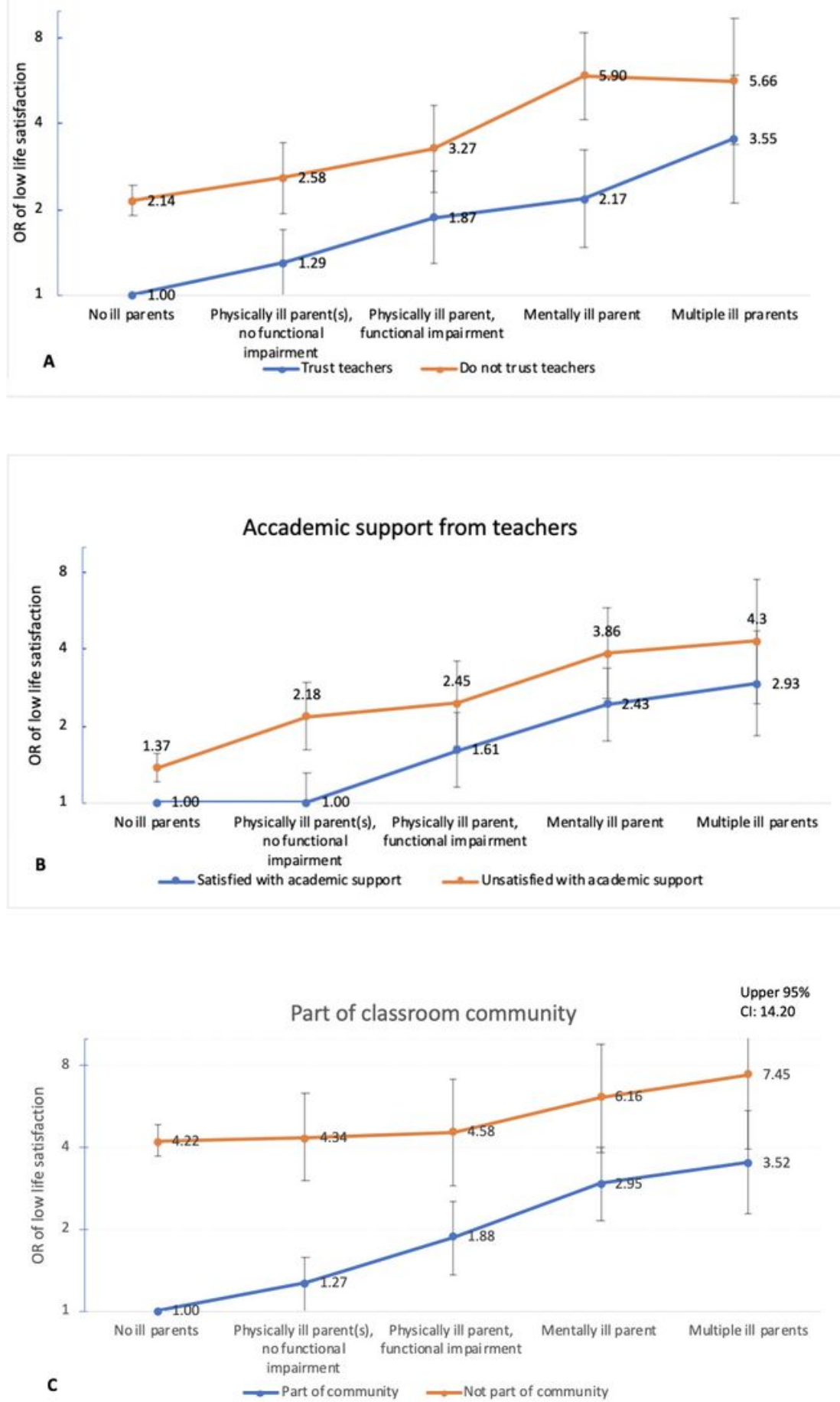

\section{Figure 1}

Odds ratios of low life satisfaction by joint effect of parental illness and school climate indicators 